\title{
Prevalence of micronutrient deficiency particularly of iron, zinc and folic acid in pregnant women in South East Asia
}

\author{
Subadra Seshadri \\ Department of Foods and Nutrition, MS University of Baroda, Vadodara 390002, India
}

\begin{abstract}
Micronutrient deficiency, whether clinical or subclinical, may affect growth, cognition and reproductive performance. In pregnant women moderate to severe deficiencies of iron, zinc and folic acid have been shown to increase risk of low birth weight, pregnancy complications and birth defects. Any attempt to introduce a micronutrient supplementation programme during pregnancy must be based on adequate data on the prevalence of micronutrient deficiencies, their adverse effects and the potential for reversing these through supplementation. This paper reviews parameters for assessment of iron, zinc and folic acid deficiencies in pregnancy and the available data on prevalence of these in pregnant women in South Asia. Iron deficiency and anemia affect $50 \%$ or more of pregnant women, the prevalence of folic acid deficiency may be up to $30-50 \%$ and there is evidence to suggest that zinc deficiency is likely to be widespread but supportive data are scarce.
\end{abstract}

Iron: Folic acid: Zinc: Deficiency

Micronutrients encompass vitamins and minerals which are essential for normal human development and functioning and are needed in minute quantities. Although the fact that human adults require only about $1 \mathrm{mg}$ of absorbable iron per day, the problem of iron deficiency anemia is widespread, especially among women of reproductive age. Several other micronutrients are known to be lacking in diets, particularly of the socio-economically weaker and physiologically vulnerable sections of the population in developing countries.

While iron deficiency anemia, especially the more severe form has been shown to be associated with increased maternal mortality, even mild iron deficiency anemia may increase the rate of premature delivery and perinatal mortality (Carriaga et al. 1991). Folic acid deficiency in pregnancy is a contributing factor to maternal anemia (Sood et al. 1975; Batu et al. 1976) and addition of folic acid supplements to iron has been shown to increase birth weight by $200 \mathrm{~g}$ on average in pregnant Indian women (Iyengar \& Rajalakshmi, 1975). Several studies have shown an association between maternal plasma zinc levels and birth weight (Neggers et al. 1990). Maternal morbidities such as pregnancy induced hypertension, prolonged labour and pre- and post-term deliveries may be increased in zinc deficient pregnant women (Swanson \& King, 1987). These observations highlight the need to define the magnitude of these deficiencies during pregnancy so that the need for appropriate interventions can be objectively ascertained.

Several factors contribute to the widespread prevalence of micronutrient deficiencies in South Asia. These include a low dietary intake, low bioavailability as in the case of iron and zinc, poor utilization due to environmental factors such as poor hygiene that lead to increased infections and infestations, adverse nutrient-nutrient interactions (Sandström, 2000) and genetic causes (Seshadri, 1997). Given this multiplicity of factors, a host of indicators, direct and indirect, are needed to assess the magnitude of the problem of micronutrient deficiencies.

The direct indicators include dietary intake, blood or tissue levels of the micronutrient, and the levels of enzymes or hormones dependent upon the micronutrient for their functions. The indirect indicators include an assessment of environmental factors that reduce absorption and utilization or increase excretion, thus creating states of deficiency.

This review will focus on the prevalence of iron, zinc and folic acid deficiencies during pregnancy, particularly in South Asia. It covers three broad areas; indictors that are available for assessing the extent of iron, zinc and folic acid deficiencies, limitations to their use in pregnancy and the magnitude of these deficiencies in India and other South Asian countries.

\section{Indicators of iron, zinc and folic acid deficiencies}

\section{Iron}

Of the many micronutrients that are considered lacking in the diets of pregnant women, iron is the most extensively investigated. This is because anemia, attributable to iron deficiency is a major problem in developing countries (WHO, 1992) and iron deficiency with or without anemia is reported to affect about $25 \%$ of the poorer pregnant 
women even in developed countries like the United States of America (Beard, 1994). Unique to iron is also the very high iron cost of pregnancy (1000 mg/pregnancy) compared to other micronutrients such as zinc or folic acid. Although iron stores can be mobilized to meet this requirement, women in general are found to have low iron stores (Beard, 1994) and pregnant women in particular may have no stores of iron at all (Carriaga et al. 1991). Under these conditions of depleted iron stores in pregnancy, dietary iron can be utilized with greater efficiency (Whittaker et al. 1991) but such a compensatory increase in iron absorption is also insufficient to prevent anemia in pregnant women, who have a greatly enhanced need.

Iron deficiency is usually considered to develop in three sequential stages; depletion of iron stores, iron deficient erythropoiesis and overt anemia with low hemoglobin $(\mathrm{Hb})$ levels.

The direct indicators for assessment of iron deficiency use blood parameters that are reflective of one or more of the above stages. The earliest sign of iron deficiency is a depletion of iron stores that can be assessed by staining the bone marrow for iron (Bothwell et al. 1979). A high correlation has been shown between stainable iron in bone marrow and serum ferritin levels (Lipschitz et al. 1974). Since serum ferritin estimation is carried out more readily and serves as an indicator of iron reserves in the body, it has been used extensively in assessing the magnitude of iron deficiency, often in conjunction with $\mathrm{Hb}$ levels. Serum ferritin levels below $12 \mathrm{mcg} / \mathrm{L}$ are indicative of depleted iron stores (Beard, 1994) in the general population.

An alternative to serum ferritin has been suggested recently, namely, transferrin receptors (TfR). Serum TfR increases in iron deficiency unlike serum ferritin and appears to be more promising (Skikne et al. 1990). The TfR rises only when iron stores are exhausted and serum ferritin has fallen below $12 \mathrm{mcg} / \mathrm{L}$ and therefore, it is considered a good indicator of functional iron deficiency. A study by Carriaga et al. (1991) which estimated serum TfR in 176 pregnant women in the third trimester found that among thirteen women who were iron deficient and anaemic, eleven had elevated serum TfR indicating that TfR was a good indicator of functional iron deficiency. Although similar results have been reported with pregnant women in Zaire by Kuvibidila et al. (1994), there was also considerable overlap in the TfR between subjects with serum ferritin levels $<12 \mathrm{mcg} / \mathrm{L}$ and $>12 \mathrm{mcg} / \mathrm{L}$.

When iron supply to the hemopoietic tissues declines, there is an elevation in the free serum erythrocyte protoporphyrin level due to inadequate iron to combine with it. Therefore, erythrocyte protoporphyrin is used for diagnosing iron deficient erythropoiesis. The cut-offs commonly used to determine the presence of iron deficiency are $>35 \mathrm{mcg} / \mathrm{dL}$ whole blood, $>80 \mathrm{mcg} / \mathrm{dL}$ $\mathrm{RBC},>3.0 \mathrm{mcg} / \mathrm{g} \mathrm{Hb}$ and $>70$ mole per mole of heme. Erythrocyte protoporhyrin levels have been found to correlate with serum ferritin.

Some studies have shown that erythrocyte zinc protoporphyrin correlates well with plasma ferritin and may be of value in identifying iron deficiency in the absence of anemia (Jensen et al. 1990). However, a study by Milne et al. (1990) in which response of various iron status indicators to iron depletion was investigated in eleven women aged 22-23 years, the relative sensitivities of different indices for detecting iron depletion was found to be serum ferritin $>\%$ transferrin saturation $>$ plasma iron $>\mathrm{Hb}>$ hematocrit (Hct) $>$ zinc protoporphyrin and erythrocyte protoporphyrin, indicating that zinc protoporphyrin is inferior to $\mathrm{Hb}$ estimation.

Hemoglobin, the most extensively used parameter, is a reflection of end stage iron deficiency. Anemia has been traditionally used as an index of iron deficiency in pregnancy but physiological alteration in plasma volume and red cell mass during pregnancy diminishes its reliability. A single $\mathrm{Hb}$ estimation may be insensitive and non-specific. Hemoglobin response to iron treatment is more sensitive and specific and it is a relatively simple parameter to use in the field setting; however, hemodilution may mask the response to therapeutic iron supplementation in iron deficient pregnant women. During pregnancy a combination of low $\mathrm{Hb}$ and low serum ferritin is recommended to detect anemia due to iron deficiency because other causes of anemia such as infections are not characterized by low serum ferritin levels.

Given the interaction between several dietary constituents and iron which result in poor absorption of iron (Yip \& Dallman, 1996), total dietary iron intake by itself is not a valid indicator of iron deficiency in the population unless it is accompanied by a reliable estimate of the bioavailability of iron. Bioavailable iron intake, especially its distribution in comparison with distribution of requirements for different age and sex groups can provide useful information concerning the extent of deficiency. Such an approach is currently not feasible at the population level, as we do not have readily available methods for estimating the bioavailable iron.

The indirect indicators that could give a rough estimate of iron deficiency problems in the population are the extent of parasitic infestations and infections, which are indicative of poor utilization of iron.

\section{Zinc}

Ever since it was shown that acrodermatitis enteropathica, a genetic disorder characterized by severe zinc deficiency, resulted in abnormal pregnancy outcomes (Hambidge \& Neldner, 1978), the search for suitable indicators for a satisfactory assessment of mild zinc deficiency in pregnant women has been actively pursued. It is reported that mild or marginal zinc deficiency must be common in several regions of the world (Prasad, 1989). However, little direct evidence of mild to moderate zinc deficiency is available, because the validity of biochemical indicators of zinc status are not established (Caulfield et al. 1998).

The most commonly used, however, is the serum or plasma zinc levels, a reduction implying a state of deficiency (Prasad, 1989). The others which have been investigated to a limited extent include erythrocyte zinc, cellular levels such as platelet, mononuclear cells or PMNL; plasma metallathionein and certain enzymes such as alkaline phosphatase, (King, 1990; Cousins, 1996). Serum thymulin, a zinc hormone involved in stimulation of T-cells is also reported to decrease in zinc deficiency 
although few investigations have used this in assessing the extent of zinc deficiency in pregnant women. Urinary excretion of zinc is reduced in zinc deficiency but it has been reported to be of limited use (Swanson \& King, 1987).

Assessment of dietary intake is impeded by lack of adequate data on zinc content of foods (Nageswara Rao \& Narasinga Rao, 1981). Further zinc bioavailability, as in the case of iron is an important determinant of zinc adequacy but methods for estimation of zinc bioavailability are not easily available. Assessment of the magnitude of mild and moderate zinc deficiency in the population is, therefore, not easily accomplished, but some available data will be reviewed later.

\section{Folic acid}

Serum and red cell folic acid are considered to be reliable direct indicators of folic acid status and are most commonly used. Serum folic acid is considered to reflect current intakes of folic acid while red cell folic acid is an indicator of long term status, as folic acid is incorporated during early development of red cells into the reticulocytes (Selhub \& Rosenberg, 1996). Urinary excretion of tetrahydrofolic acid has been used to assess folate status in some studies (Caudill et al. 1997).

Highly specific methods for the assessment of vitamin $\mathrm{B}_{12}$ and folate status have been developed, namely by determination of serum methylmalonic acid (MMA) and homocysteine (Hcy), respectively (Schneede et al. 1994; Refsum et al. 1989).

\section{Limitations to the use of these indicators in pregnancy}

There are several factors other than the total body pool of the nutrients under consideration that affect the levels of the indicators discussed in the earlier section. Serum ferritin, plasma levels of zinc and other concentration dependent indicators such as $\mathrm{Hb}$ and transferrin saturation suffer from the limitation that the expansion in plasma volume which occurs during pregnancy produces a reduction in the levels of these indicators, even when there is no change in the total body pool of these nutrients. The serum ferritin cut off of $12 \mathrm{mcg} / \mathrm{L}$ may overestimate the prevalence of iron deficiency in pregnancy if no attempt is made to take into account the hemodilution effect. A similar pattern is observed with plasma zinc levels. A consistent finding in several studies is the plasma zinc reduction as pregnancy advances, which is unrelated to dietary intakes. The plasma zinc values reported in the first trimester are 10.4 to $13.9 \mu \mathrm{mol} / \mathrm{L}$ while in the third trimester there was a clear decline; values ranged from 8.4 to $9.8 \mu \mathrm{mol} / \mathrm{L}$ (Hambidge \& Drogemuellag, 1974; Cherry et al. 1981; Meadows et al. 1981; Hambidge et al. 1983; Breskin et al. 1983; Zinnerman, 1984; Quist et al. 1986). In a study carried out in India the mean plasma zinc in pregnant women in the first trimester was $9.2 \mu \mathrm{mol} / \mathrm{L}$ which was reported to decline as pregnancy advanced to 8.3 and $8.6 \mu \mathrm{mol} / \mathrm{L}$ in the second and third trimester (Mukherjee et al. 1984). Therefore gestation specific cut off values need to be developed.

The second limitation relates to the variation which occurs in some of these indices due to infections and inflammation. Serum ferritin levels are increased by both acute and chronic inflammation, as it is an acute phase reactant. It has been shown for instance, that in acute and chronic inflammatory conditions, the serum ferritin concentration is increased three times higher for each grade of bone marrow staining, as compared to controls without any inflammatory condition. Therefore, $12 \mathrm{mcg} / \mathrm{L}$ may not be an adequate cut off to exclude iron deficiency in populations that suffer from chronic inflammatory conditions. The recommendation is that chronic inflammation be assessed concurrently using suitable parameters and in the presence of inflammation, a cut off value of $50 \mathrm{mcg} / \mathrm{L}$ is suggested to be indicative of iron depletion (Beard, 1994).

The third limitation relates to the validity of the measure for the purpose for which it is used. For example, serum ferritin levels are considered as indicative of the extent of iron stores, each $\mathrm{mcg} / \mathrm{L}$ of serum ferritin corresponding to $10 \mathrm{mg}$ storage iron. These studies were conducted in nonpregnant subjects and there is some reservation that this quantitative relationship may not hold true in pregnancy (Beard, 1994).

The last of the limitations is the considerable day-to-day within-subject variation that is reported to occur in some parameters, independent of the size of the total pool. For example, in the case of serum ferritin the coefficient of dayto-day variation is reported to approach 25-40 \% (Beard, 1994), whereas such variation for $\mathrm{Hb}$ and $\mathrm{Hct}$ is reported to be much lower. This smaller variation allows a higher level of confidence with a single determination of $\mathrm{Hb}$ whereas with serum ferritin, to achieve the same level of confidence, it is reported that at least ten repeated daily measures will be needed (Beard, 1994).

Even with $\mathrm{Hb}$, with the smaller within person variation, some investigators have shown that repeated measures would reduce the false positives (individuals classified as iron deficient when they are not). This approach has not been used with pregnant women populations but appears to hold promise in assessing the population prevalence of iron deficiency anemia.

A limitation with respect to the use of plasma zinc levels for assessment of zinc deficiency is that it is not sensitive to variations in dietary intakes within the normal range observed in pregnant women. The absorption of zinc is adjusted with varying levels of intake so that the plasma zinc levels are maintained. Only under moderate or severe deficiency of intake, when the capacity to maintain homeostasis is exceeded, do plasma levels start declining (Milne et al. 1990). In addition to this, there is also improved efficiency of absorption during pregnancy.

\section{Prevalence of iron, zinc and folic acid deficiencies in pregnant women}

\section{Iron}

Despite the limitations of $\mathrm{Hb}$ as an indicator, anemia prevalence as an index of iron deficiency has been studied in India and other South Asian countries. As a part of the evaluation of the national nutritional anemia control programme, the Indian Council of Medical Research 
(ICMR) coordinated studies in eleven states of India in which $\mathrm{Hb}$ estimations were done on 4775 pregnant women above 20 weeks of gestation. Eighty-seven per cent of the women were found to be anaemic, with Hb less than $11 \mathrm{~g} / \mathrm{dL}$. The prevalence in other South Asian countries has been estimated to be; Bangladesh $77 \%$, Bhutan $59 \%$, Nepal $65 \%$ and Sri Lanka $60 \%$ (Seshadri, 1997).

Since $\mathrm{Hb}$ per se does not provide an indication of the extent of iron deficiency, some studies have used both $\mathrm{Hb}$ $<11 \mathrm{~g} / \mathrm{dL}$ and serum ferritin below $10 \mathrm{mcg} / \mathrm{L}$ to assess anemia due to iron deficiency. As seen from Table 1, the prevalence of iron deficiency is $50 \%$ or more in pregnant women accounting for most of the anemia seen in these subjects. We carried out a therapeutic supplementation trial in 120 pregnant women who were followed up from 20 weeks of gestation till 32-36 weeks. The initial prevalence of anemia in this group was $88 \%$. A positive response in $\mathrm{Hb}$ of $1 \mathrm{~g} / \mathrm{dL}$ or more was seen in $90 \%$ of the eighty women who were treated with $120 \mathrm{mg}$ or $180 \mathrm{mg}$ of iron and in $54 \%$ of the forty women treated with $60 \mathrm{mg}$. All women received the same level of folic acid $(0.5 \mathrm{mg} /$ day). These data, although limited, provide evidence of widespread iron deficiency in pregnant women, affecting $50 \%$ or more and contributing to the major proportion of anemia seen in developing countries.

\section{Zinc}

As of now the prevalence of marginal or sub-optimal zinc nutriture is not known with certainty. Given that no single indicator reflects zinc status adequately, a battery of measures is suggested, which includes measurement of zinc concentration in blood, the amount of zinc in the diet, determination of a zinc-dependent enzyme like alkaline phosphatase and $24 \mathrm{~h}$ urinary excretion of zinc, but in the available studies plasma or serum zinc levels have been mostly used. While definite data on the prevalence of zinc deficiency are hard to come by, several studies in the literature highlight the likelihood of widespread marginal zinc deficiency in pregnant women. The zinc concentration in plasma of pregnant women of Indian origin is shown to be significantly lower than that of white pregnant women in Natal, South Africa, apparently related to lower dietary intakes (Duncan, 1988). Another study in the USA, which investigated the relationship between maternal serum zinc levels and birth weights of infants found that the prevalence of low birth weight increased significantly in women who had serum zinc levels in the lowest quartile and suggested that there is a threshold for serum zinc concentration below which the occurrence of adverse pregnancy outcomes may increase significantly (Neggers et al. 1990) and this threshold level may be considered as a functional indicator for assessing the prevalence of zinc deficiency.

Using estimated usual intakes reported in the literature (Parr, 1996) and the estimated distribution of zinc required by women to meet their normative needs during pregnancy, Caulfield et al. (1998) have derived that $82 \%$ of the pregnant women worldwide are likely to have inadequate usual intakes of zinc. In yet another observation, Caulfield et al. (1999) have reported that $60 \%$ of pregnant women from an impoverished area in Lima, Peru were found to have serum zinc concentrations less than $9.18 \mu \mathrm{mol} / \mathrm{L}$ indicating some degree of maternal zinc deficiency. However, a study from Thailand which investigated zinc and copper status in ninety-six Thai women attending an antenatal clinic found $96 \%$ of the subjects to have normal serum zinc and copper levels, inspite of the dietary intakes meeting only $34 \%$ of the Thai RDA for zinc and $69 \%$ of the Thai RDA for copper. The authors therefore, concluded that these subjects were not at risk of zinc deficiency despite a low intake of zinc $(6.9 \mathrm{mg} / \mathrm{d})$. To be noted, however, is that $55 \%$ of the zinc intake was from animal sources, known to have higher bioavailability (Songchitsomboon et al. 1998).

Evidently, more studies are needed to define the parameters for measurement of zinc deficiency in pregnancy and the extent of deficiency in South Asia.

\section{Folic acid}

There is greater consensus regarding the indicators for assessment of folate status, although gestation-specific criteria are not well determined. A serum folic acid level of less than $3 \mathrm{ng} / \mathrm{ml}$ and a red cell folic acid level of less than $100 \mathrm{mg} / \mathrm{dL}$ are considered indicative of folate deficiency. Data on pregnant women from different developing countries however are scarce. The World Health Organization (1992) compiled available information on the prevalence of anemia, which included the prevalence of folic acid and vitamin $B_{12}$ deficiency. The percentage of pregnant women with a serum folic acid level less than $3 \mathrm{ng} / \mathrm{ml}$ was highest among pregnant women in Sri Lanka $(57 \%)$, followed by India (41.6\%), Myanmar (13\%) and Thailand (15\%) (WHO, 1992; Basu et al. 1973).

From a nutritional perspective, much of the interest in folic acid deficiency has centred around low birth weight and neural tube defects. However, with recent observations of elevated homocysteine levels in folic acid deficiency and the implications for increased risk of cardiovascular diseases, studies on folic acid deficiency should receive a higher priority in future.

Table 1. Magnitude of iron deficiency in pregnant women

\begin{tabular}{llccc}
\hline Place & \multicolumn{1}{c}{ Reference } & Number & Anemia \% & Iron deficiency \% \\
\hline Chad, Africa & Prual et al. 1987 & 112 & 25 & 67 \\
Hyderabad, India & Raman et al. 1989 & 283 & $70-80$ & 49 \\
Beijing, China & Wang et al. 1990 & 100 & 34 (II) & 35 (II) \\
Nigeria & & & 36 (III) & 49 (II) \\
\hline
\end{tabular}




\section{Conclusions}

In summary, the magnitude of iron deficiency in pregnancy is best documented by using a battery of indicators. The existing studies indicate that at least $50 \%$ of the pregnant women in South Asian countries are iron deficient and anaemic. Folic acid deficiency, although not quite as common as iron deficiency, yet nearly $40-50 \%$ of pregnant women may suffer from some degree of deficiency. The extent of zinc deficiency needs to be determined through further studies. There are few studies, which have assessed prevalence of multiple micronutrient deficiencies in the same pregnant women. It appears likely that the women who belong to the lower socio-economic groups and suffer from dietary deprivation are likely to suffer from iron, zinc, folic acid and possibly other deficiencies. As the main concern is to improve maternal and infant health, interventions to enhance the intake of several micronutrients should be considered.

\section{References}

Basu RN, Sood SK, Ramachandran K, Mathur M \& Ramalingaswamy V (1973) Etiopathogenesis of nutritional anemia in pregnancy: a therapeutic approach. American Journal of Clinical Nutrition 26, 591-594.

Batu AT, Thane T, Pe H \& Nyunt KK (1976) A prophylactic trial of iron and folic acid supplements in pregnant Burmese women. ISV Journal of Medical Sciences 12, 1410-1417.

Beard JL (1994) Iron deficiency: assessment during pregnancy and its importance in pregnant adolescents. American Journal of Clinical Nutrition 59 (Suppl.), 5025-5105.

Bothwell TH, Charlton RW, Cook JD \& Finch CA (1979) Iron Metabolism in Man. London: Blackwell Scientific Publications.

Breskin MW, Worthington-Roberts BS, Knopp RH, Brown Z, Plovie B, Mottet NK \& Mills JL (1983) First trimester serum zinc concentration in human pregnancy. American Journal of Clinical Nutrition 38, 943-953.

Carriaga TM, Skikne BS, Finley B, Cutler B \& Cook J (1991) Serum transferring receptor for the detection of iron deficiency in pregnancy. American Journal of Clinical Nutrition 54, 1077-1081.

Caulfield LE, Zvaleta N, Shankar A \& Merialdi M (1998) Potential contribution of maternal zinc supplementation during pregnancy to maternal and child survival. American Journal of Clinical Nutrition 68 (Suppl.), 4995-5085.

Caulfield LE, Zavaleta N \& Figuroa A (1999) Adding zinc to prenatal iron and folate supplements improves maternal and neo-natal zinc status in a Peruvian population. American Journal of Clinical Nutrition 69, 1257-1263.

Caudill MA, Cruz AC, Gregory JF \& Huston AD (1997) Folate status response to controlled folate intake in pregnant women. Journal of Nutrition 127, 2363-2370.

Cherry FF, Bennett EA, Bazzano GS, Johnson LK, Fosmire GJ \& Batson HK (1981) Plasma zinc in hypertension/toxemia and other reproductive variables in adolescent pregnancy. American Journal of Clinical Nutrition 34, 367-375.

Cousins RJ (1996) Zinc. In Present Knowledge in Nutrition [EE Ziegler and LJ Filer Jr, editors]. Washington, DC: ILSI Press.

Daouda H, Galan P, Prual A, Sekou H \& Herceberg S (1991) Iron status of Nigerian mothers and their newborns. International Journal of Vitamin and Nutrition Research 61, 46-50.

Duncan JR (1988) Zinc nutriture in pregnant and lactating women in different population groups. South African Medical Journal 73, 160-162.
Hambidge KM \& Drogemuelleg W (1974) Changes in plasma and hair concentrations of zinc, copper, chromium and manganese during pregnancy. Obstetrics and Gynecology 44, 666-672.

Hambidge KM \& Neldner KH (1978) Zinc and copper in clinical medicine. Cf Prasad, AS. Proceedings of the Nutrition Society of India 35, 1-12.

Hambidge KM, Krebs NF, Jacobs MA, Favier A, Gvyette L \& Ikle DN (1983) A prospective study of serial maternal serum zinc levels and pregnancy outcome. Early Human Development 7, 59-69.

Iyengar L \& Rajalakshmi K (1975) Effect of folic acid supplement on birth weight of infants. American Journal of Obstetrics and Gynecology 122, 332-336.

Jensen BM, Sando SH, Grandjean P, Wiggers P \& Dalhoj J (1990) Screening with zinc protoporphyrin for iron deficiency in nonanemic female blood donors. Clinical Chemistry 36, 487-491.

King JC (1990) Assessment of zinc status. Journal of Nutrition 11 (Suppl), 1474-1479.

Kuvibidila S, Yu CL, Ode DL, Warrier RP \& Mbele V (1994) Assessment of iron status of Zairean women of child bearing age by serum transferrin receptor. American Journal of Clinical Nutrition 60, 603-609.

Lipschitz DA, Cook JD \& Finch CA (1974) A clinical evaluation of serum ferritin as an index of iron stores. New England Journal of Medicine 29, 1213.

Meadows NJ, Ruse W, Smith MF, Day J, Keeling PW, Scopes JW, Thompson RP \& Bloxam DL (1981) Zinc and small babies. Lancet 2, 59-69.

Milne DB, Gallagher SK \& Nielsen FH (1990) Response of various indices of iron status to acute iron depletion produced in women by low iron intake and phelebotomy. Clinical Chemistry 36, 487-491.

Mukherjee MD, Sandsted HH, Ratnaparkhi MU, Johnson LK, Milne DB \& Stelling HP (1984) Maternal zinc, iron, folic acid and protein nutriture and outcome of pregnancy. American Journal of Clinical Nutrition 40, 496-507.

Nageswara Rao C \& Narasinga Rao BA (1981) Trace element content of Indian foods and the dietaries. Indian Journal of Medical Research 73, 904-909.

Neggers YH, Cutler GR, Action RT, Alvarej JA, Bonner JL, Goldenberg RL, Go RCP \& Roseman JM (1990) A positive association between maternal serum zinc concentration and birth weight. American Journal of Clinical Nutrition 51, 678-684.

Parr RM (1996) Assessment of dietary intakes. In Trace Elements in Human Nutrition and Health, pp. 265-288. Geneva: World Health Organization.

Prasad AS (1989) Human zinc deficiency. Proceedings of the Nutrition Society of India 35, 1-12.

Prual A, Galan P, Bernes L \& Herceberg S (1990) Iron status at the end of pregnancy: Consequences of maternal iron deficiency on the iron status of the newborn. Nutrition Abstracts and Reviews 60 (1), 141.

Quist I, Abdulla M, Jagerstad M \& Svenson S (1986) Iron, zinc and folate status during pregnancy and two months after delivery. Acta Obstetrica Gynecologica Scandinavia 65, 15-22.

Raman L, Subbalakshmi PV, Vasumati N, Rawal A, Vasanthi G, Parvathi CH, Adinarayana K, Pawashe AB \& Rao KV (1989) Iron and folic acid. Nutritional Reports International 39, 493-502.

Refsum H, Ueland PM \& Svardal AM (1989) Fully automated fluorescence assay for determining total homocysteine in plasma. Clinical Chemistry 35, 1921-1927.

Sandström B (2000) Micronutrient interactions: effects on absorption and bioavailability. In press.

Schneede J, Dagnelie PC, van Staveren WA, Vollset SE, Refsum H \& Ueland PM (1994) Methylmalonic acid and homocysteine in plasma as indicators of functional cobalamin deficiency in infants on macrobiotic diets. Pediatric Research 36, 194-201. 
Seshadri S (1997) Nutritional anemia in South Asia. In Malnutrition in South Asia - A Regional Profile, pp. 75-124 [S Gillespie, editor]. UNICEF Regional Office for South Asia. Selhub J \& Rosenberg IH (1996) Folic acid. In Present Knowledge in Nutrition, pp. 206-219 [EE Ziegler and LJ Filer, editors]. Washington DC: ILSI Press.

Skikne B, Flowers CH \& Cook JD (1990) Serum transferring receptor. A quantitative measure of tissue iron deficiency. Blood 75, 1870-1876.

Songchitsomboon S, Komindr S, Phuarpnadit W \& Sirivarasae J (1998) Zinc and copper status in urban Thai pregnant women and their pregnancy outcome. Biomedical and Environmental Sciences 11, 156-164.

Sood SK, Ramachandran K, Mathur M, Gupta K, Ramalingaswamy V, Swarnabai C, Ponniah J, Mathan VI \& Baker SJ (1975) WHO sponsored collaborative studies on nutritional anaemia in India. 1 The effects of supplemental oral iron administration to pregnant women. Quarterly Journal of Medicine 44, 241-258.
Swanson CA \& King JC (1987) Zinc and pregnancy outcome. American Journal of Clinical Nutrition 46, 763-771.

Wang H, Chen XC \& Wang WC (1990) Nutritional status of gestating Chinese women and its influence upon neonates with emphasis on iron. Nutrition Research 10, 493-502.

Whittaker PG, Lind T \& Williams JG (1991) Iron absorption during normal human pregnancy: a study using stable isotopes. British Journal of Nutrition 65, 457-463.

WHO (1992) The prevalence of anemia in women: a tabulation of available information. Maternal Health and Safe Motherhood and Nutrition Programme. Geneva: World Health Organization.

Yip R \& Dallman PR (1996) Iron. In Present Knowledge in Nutrition, pp. 277-292 [EE Ziegler and LJ Filer, editors]. Washington DC: ILSI Press.

Zinnerman AW, Dienham BS, Nochimson DJ, Kaplan BM \& Kunkel SL (1984) Zinc transport in pregnancy. American Journal of Obstetrics and Gynecology 149, 523-528. 